\title{
Sciendo
}

ISSN: $1231-4005$

e-ISSN: $2354-0133$

DOI: $10.2478 /$ kones-2019-0088

\section{MECHANICAL PROPERTIES OF AW-5083 ALLOY JOINTS WELDED BY HYBRID METHOD - FSW AND MIG}

\author{
Krzysztof Dudzik \\ Gdynia Maritime University, Faculty of Marine Engineering \\ Morska Street 81-87, 81-225 Gdynia, Poland \\ tel.: +48585586549, fax: +48585586399 \\ e-mail:k.dudzik@wm.umg.edu.pl
}

\begin{abstract}
The article presents the research results on the mechanical properties of aluminum alloy AW-5083 and its joints welded by hybrid method - traditional MIG and FSW. AW-5083 alloy is the most currently used in shipbuilding industry. Friction Stir Welding (FSW) - a new technology can be successfully used for butt-welding of different types of aluminum alloy sheets. FSW method can be an alternative to traditional arc welding methods i.e. MIG or TIG. Hybrid welding (FSW with MIG or TIG) could be used in cases when joining only by FSW is not possible. Welding parameters used for the connection of the sheets were presented. Metallographic analysis showed the correct construction of structural bonded joints. The research was carried out using a static tensile test in accordance with the requirements of the Standard PN-EN ISO 4136:2013-05. Flat samples cut perpendicular to the direction of rolling were used. The research was conducted at the temperature of $+20^{\circ} \mathrm{C}$. The test shows that the mechanical properties of joints made by hybrid method compered to native material were lower. The tensile strength of joint was lower by $20 \%$ then native material 5083 while its yield stress was lower only about 6\%. The biggest change was observed in case of plastic properties. Elongation of joint was over 50\% lower compared to native material. Despite the decrease of mechanical properties, they meets the requirements of classification societies, so the conclusion is that hybrid method (FSW and MIG) of joining AW-5083 can be applied in shipbuilding industry.
\end{abstract}

Keywords: hybrid welding, Friction Stir Welding (FSW), welding, MIG, aluminium alloys, joints, mechanical properties, shipbuilding

\section{Introduction}

Aluminium alloys are materials, which find worldwide industrial applications, including shipbuilding. Their application to ship hull structures is increasing as the alloys make it possible to lower significantly mass of structures as compared with that of steel structures. By using Al-alloys lowering the mass by about $50 \%$ can be obtained, which makes it possible to increase ship buoyancy, or at maintained buoyancy to increase its load carrying capacity or speed, as well as to improve its stability [2]. For that reasons Al-alloys are used i.e. for construction of ship hull and superstructures. Among weldable Al-alloys suitable to plastic working the group of Al-Mg alloys (of 5xxx- series) of good weldability and relatively good service conditions are still the most popular $[3,5,7,12]$. Their relative insuspectibility to layer and stress corrosion is advantageous, and their disadvantage is low strength of welded joints of elements made of them, not exceeding $300 \mathrm{MPa}$ [4]. Nowadays Al-Mg alloys of 5xxx- series are the only materials applicable to hull structures of lightweight ships $[1,5,6,8]$.

An alternative to traditional methods such as MIG or TIG welding may be Friction Stir Welding (FSW). In the method, a tool fitted with rotary mandrel located in the place of welding the pressed-down plates is used to heat and plastify the material. After putting the mandrel-fitted tool into rotation, friction heating and plastifying the plate material in its direct vicinity occurs, and slow sliding the entire system follows along contact line $[10,11]$. Because this method consists in welding in the solid state, below the melting temperature of the material, the mechanical properties obtained using this joining method may be higher than those for arc welding techniques (MIG, 
TIG). The main advantage of this method is that it is easy to obtain joints with high, reproducible properties $[5,6,9]$. Because in the FSW method, welding occurs in the solid state, much less heat is supplied to the joined materials than is the case with conventional welding [13, 14]. This significantly reduces the size of the heat-affected zone. Unfortunately, in some cases joining only by FSW is not possible. Especially welding thick sheets or angular bonds could make problems. The solution could be using hybrid welding - in hard to reach areas of constructions it's possible using traditional MIG welding and the opposite side of joint could be made by FSW.

Chosen for testing AW-5083 aluminium alloy is the most often currently used in shipbuilding industry. The aim of this article was to determine the mechanical properties of the AW-5083 alloy joints welded by hybrid method (FSW and traditional MIG). As a reference point were chosen native material 5083 alloy.

\section{The research methodology}

The testing used EN AW-5083 (AlMg4.5Mn0.7) aluminium alloy. The chemical composition of alloy is given in Tab. 1 .

Tab. 1. Chemical composition of 5083 aluminum alloy

\begin{tabular}{|c|c|c|c|c|c|c|c|c|c|}
\hline \multicolumn{10}{|c|}{ Chemical composition [\%] } \\
\hline $\mathrm{Si}$ & $\mathrm{Fe}$ & $\mathrm{Cu}$ & $\mathrm{Mn}$ & $\mathrm{Mg}$ & $\mathrm{Cr}$ & $\mathrm{Zn}$ & $\mathrm{Ti}$ & $\mathrm{Zr}$ & $\mathrm{Al}$ \\
\hline 0.195 & 0.18 & 0.09 & 0.662 & 4.745 & 0.111 & 0.042 & 0.025 & 0.037 & balance \\
\hline
\end{tabular}

Sheet thickness was $g=12 \mathrm{~mm}$. One side of the butt weld was carried out using MIG method and an automated welding robot. The electrode wire made of the 5183 alloy (AlMg4.5Mn) - with a diameter of $1.2 \mathrm{~mm}$ was used for the welding of 5083 alloy sheets. Chemical composition of welding wire alloy is shown in Tab. 2 .

Tab. 2. Chemical composition of 5183 alloy used as welding wire

\begin{tabular}{|c|c|c|c|c|c|c|c|c|}
\hline \multicolumn{1}{|c|}{ Chemical composition [\%] } \\
\hline $\mathrm{Si}[\%]$ & $\mathrm{Fe}[\%]$ & $\mathrm{Cu}[\%]$ & $\mathrm{Mn}[\%]$ & $\mathrm{Mg}[\%]$ & $\mathrm{Cr}[\%]$ & $\mathrm{Zn}[\%]$ & $\mathrm{Ti}[\%]$ & $\mathrm{Al}[\%]$ \\
\hline 0.40 & 0.40 & 0.10 & $0.5-1.0$ & $4.3-5.2$ & $0.05-0.25$ & 0.25 & 0.15 & balance \\
\hline
\end{tabular}

The MIG welding parameters were presented in Tab. 3 .

Tab. 3. Welding parameters used for joining by MIG method

\begin{tabular}{|c|c|c|c|c|c|}
\hline $\begin{array}{c}\text { Layer } \\
\text { No. }\end{array}$ & $\begin{array}{c}\text { Current } \\
{[\mathrm{A}]}\end{array}$ & $\begin{array}{c}\text { Voltage } \\
{[\mathrm{V}]}\end{array}$ & $\begin{array}{c}\text { Gas consumption } \\
{[1 / \mathrm{min}]}\end{array}$ & $\begin{array}{c}\text { Welding speed } \\
{[\mathrm{m} / \mathrm{min}]}\end{array}$ & $\begin{array}{c}\text { Intermediate } \\
\text { temperature }\left[{ }^{\circ} \mathrm{C}\right]\end{array}$ \\
\hline 1 & 191 & 24.3 & 20 & 7.5 & 52 \\
\hline 2 & 171 & 23.1 & 20 & 6.4 & 82 \\
\hline 3 & 178 & 23.6 & 20 & 6.8 & 88 \\
\hline
\end{tabular}

The edges of the joining elements have been bevelled to the $\mathrm{Y}$ shape, so that the angle of $60^{\circ}$ on the welding side. In order to obtain the right depth of penetration, the welding process was divided into three stages. Fig. 1a shows the scheme for the preparation of bonded edges and Fig. $1 \mathrm{~b}$ the order of the layers.

The edges of the bonded sheets were cleaned of the oxide layer with a stainless steel wire brush and degreased.

The opposite side of joint was made using FSW. The diagram of friction stir welding is shown in Fig. 2 and a view of the tool used in research is presented in Fig. 3. 
a)

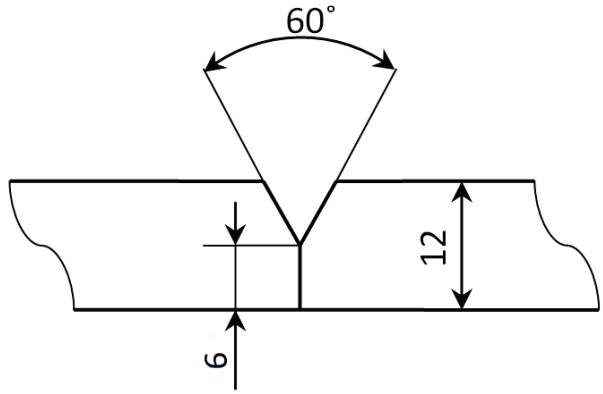

b)

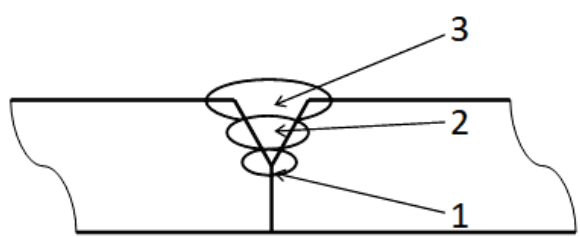

Fig. 1. Scheme of welded sheets: a) prepared edges, b) order of the layers

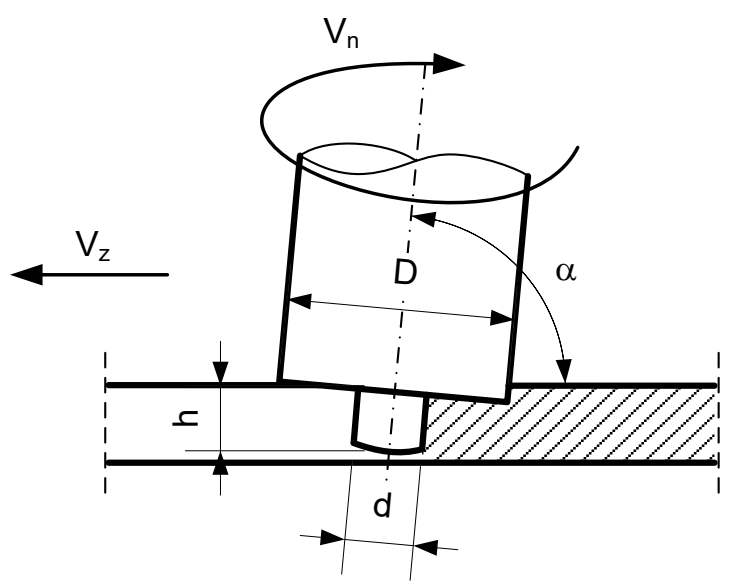

Fig. 2. The diagram of FSW

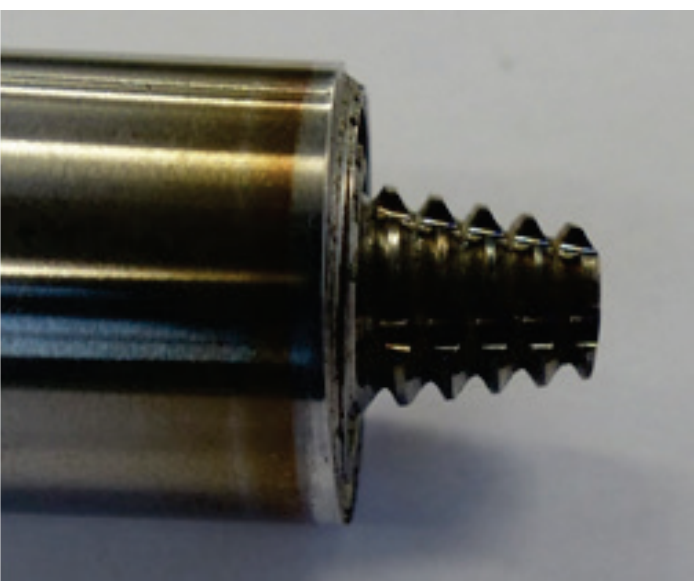

Fig. 3. View of the tool used in research

Welds made by MIG and FSW methods have been verified by X-ray flaw detection and showed no welding defects.

The parameters of FSW are shown in Tab. 4.

Tab. 4. FSW parameters of 5083 aluminium alloys sheets

\begin{tabular}{|c|c|c|c|c|c|}
\hline \multicolumn{3}{|c|}{ Tool dimensions } & \multirow{2}{*}{$\begin{array}{c}\text { Angle of tool deflection } \\
\alpha\left[^{\circ}\right]\end{array}$} & \multirow{2}{*}{$\begin{array}{l}\text { Mandrel's rotary speed } \\
\qquad V_{\mathrm{n}}[\mathrm{rpm}]\end{array}$} & \multirow{2}{*}{$\begin{array}{c}\text { Welding speed } \\
V_{z}[\mathrm{~mm} / \mathrm{min}]\end{array}$} \\
\hline $\mathrm{D}[\mathrm{mm}]$ & $\mathrm{d}[\mathrm{mm}]$ & $\mathrm{h}[\mathrm{mm}]$ & & & \\
\hline 20 & $\begin{array}{l}10-\text { in the top } \\
6-\text { in the bottom }\end{array}$ & 7.5 & 88.0 & 0 & 0 \\
\hline
\end{tabular}

In order to determine the mechanical properties was carried out static tensile test. Tensile test was carried out in accordance with PN-EN ISO 4136:2013-05. Used flat samples cut perpendicular to the direction of rolling. The specimen's dimensions are presented in Fig. 4.

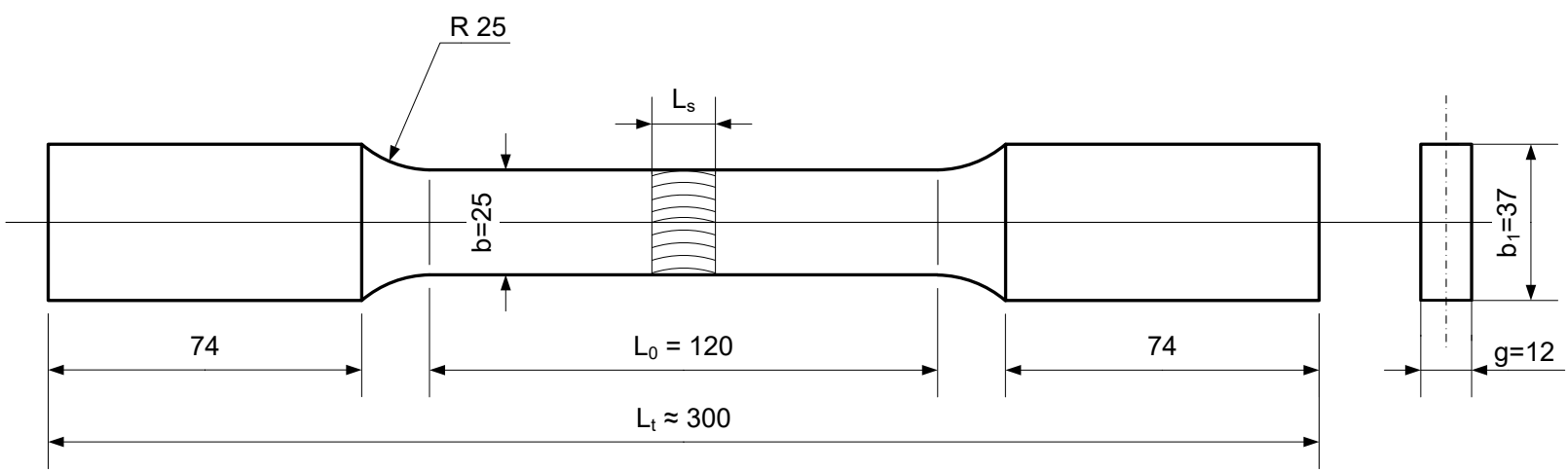

Fig. 4. The shape and dimensions of specimens used in static tensile test 
The study was performed at ambient temperature, i.e. $+20^{\circ} \mathrm{C} \pm 2$. Tensile testing was carried out on samples with flat-type testing machine Zwick/Roell HB on the strength of $100 \mathrm{kN} \pm 1$. During the study determined parameters such as ultimate tensile strength UTS, yield stress YS, and elongation EL.

\section{The research results}

The results of the static tensile test of 5083 alloy joints welded by hybrid method (MIG + FSW) are shown in Tab. 5. For comparison, the results of the test for native material AW-5083 are presented in the same table.

Tab. 5. The mechanical properties of 5083 alloy and its joints welded by hybrid method (MIG + FSW)

\begin{tabular}{|c|c|c|c|}
\hline Specimen No. & YS [MPa] & UTS [MPa] & EL [\%] \\
\hline 1 & 149.77 & 245.91 & 9.4 \\
\hline 2 & 154.09 & 252.53 & 10.9 \\
\hline 3 & 152.65 & 248.87 & 9.9 \\
\hline Average & 152.17 & 249.10 & 10.07 \\
\hline Native material & 162.91 & 309.92 & 21.88 \\
\hline
\end{tabular}

An exemplary graph of static tensile test obtained during research is shown in Fig. 5.

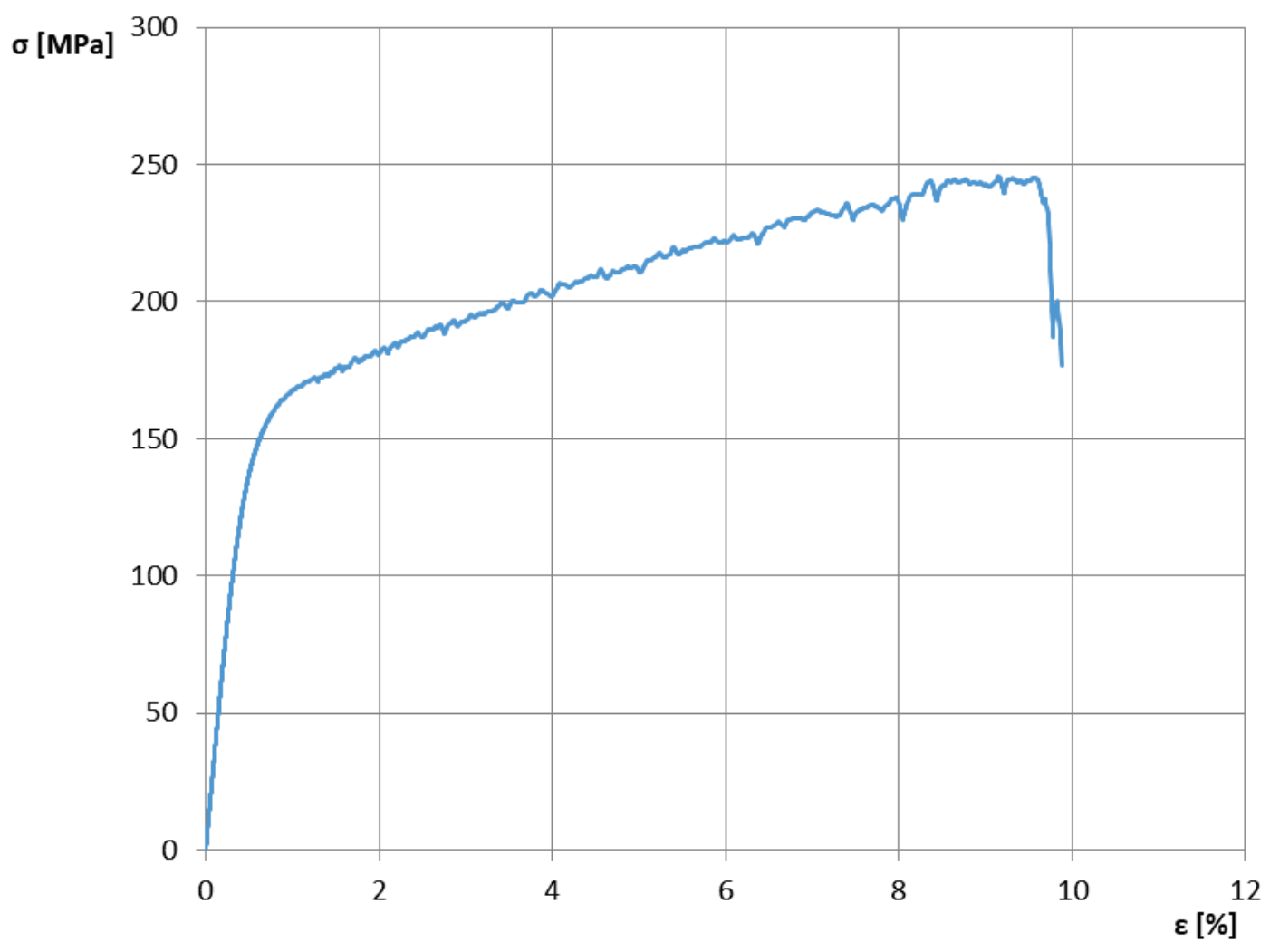

Fig. 5. An exemplary graph of static tensile test of investigated hybrid joint

Figure 6 shows a fracture of the specimen after static tensile test. The upper part of the joint was welded using the MIG method, the lower by FSW. The lower part of the specimen, welded by FSW method, has a more plastic character of the crack in comparison to the upper part, welded by MIG method.

A view of crack of specimen after static tensile test was shown in Fig. 7. 


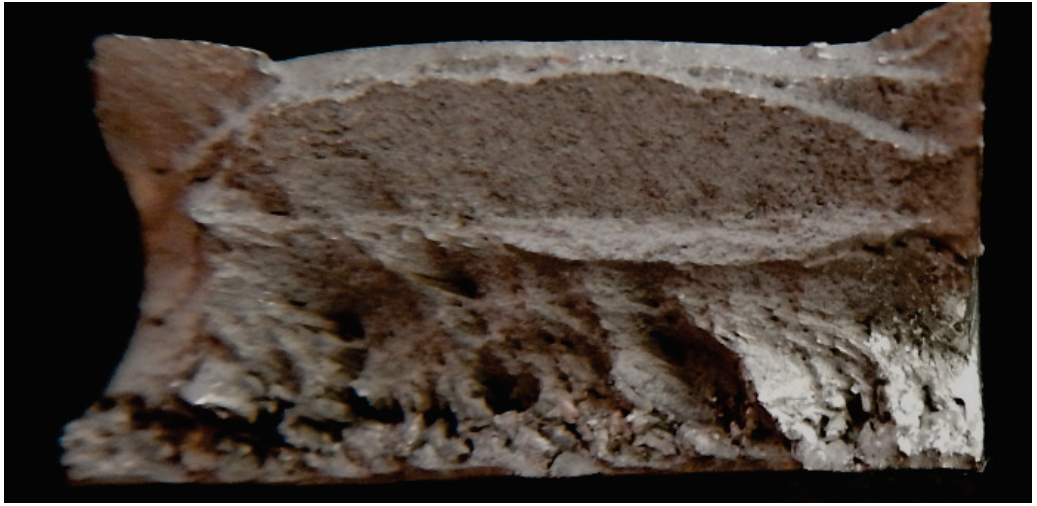

Fig. 6. Fracture of the specimen after static tensile test

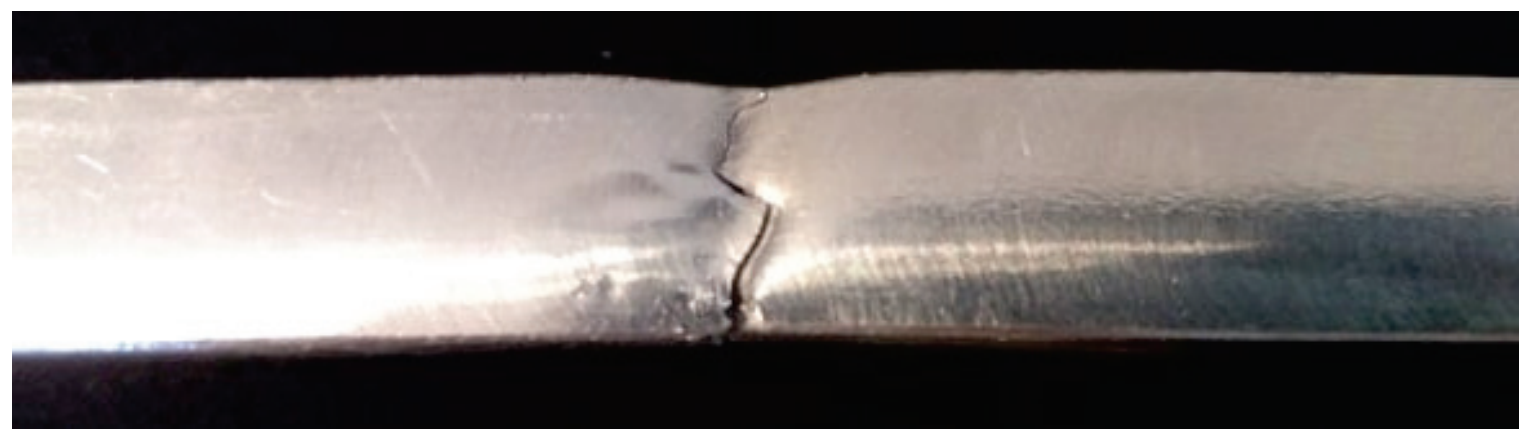

Fig. 7. A crack of specimen after static tensile test

Comparing the mechanical properties of joints made by hybrid method to native material can be seen that they are lower. The tensile strength of joint was lower by $20 \%$ then native material 5083 while its yield stress, a parameter that often is a rams into account by the designers, was lower only about $6 \%$. The biggest change was observed in case of plastic properties. Elongation of joint was over $50 \%$ lower compared to native material.

\section{Summary}

Testing the mechanical properties conducted by using a static tensile test on flat specimens of AW-5083 alloy and its joints welded by experimentally hybrid method consists of friction stir welding and traditional MIG welding showed decrease of mechanical properties of joints compared to native material.

The tensile strength of joint was lower by about $20 \%$ in comparison with native material 5083 . Average value of yield stress was similar - in case of joint was lower only about $6 \%$. The biggest change was observed in case of plastic properties. Average elongation of joint slightly exceeded $10 \%$ while for native material that parameter was over $20 \%$.

According to requirements of standards and classification societies, the ultimate tensile strength of joint must exceed $70 \%$ of native material. The research results showed that in case of AW-5083 alloy and its joints welded by hybrid method the UTS ratio - joint compared to native material was about $80 \%$.

When considering plastic properties of 5083 alloy the decrease of elongation was over 50\% comparing joint to native material. Despite so big decrease, that parameter meets the requirements of classification societies, including the PRS (Polish Register of Shipping). The minimum value of elongation must exceed $10 \%$.

The research of the mechanical properties of AW-5083 alloy and its joints welded by hybrid method - FSW and traditional MIG allow concluding that the application of those two methods together is possible to build the structure, of the investigated alloy, in shipbuilding industry. 


\section{References}

[1] Anderson, T., New developments within the Aluminium Shipbuilding Industry, Svetsaren, Vol. 58, No. 1, pp. 3-5, 2003.

[2] Czechowski, M., Effect of anodic polarization on stress corrosion cracking of some aluminium alloys, Advances in Materials Science, Vol. 7, No. 1/11, pp. 13-20, 2007.

[3] Czechowski, M., Pietras, A., Zadroga, L., The properties of aluminium alloys 5xxx series welded by new technology Friction Stir Welding, Inżynieria Materiałowa, $\mathrm{Nr}$ 6/137, pp. 264-266, 2003.

[4] Das, U., Toppo, V., Sahoo, T. K., Sahoo, R., Microstructural and Mechanical Properties of FSW Joints, Trans Indian Institute of Metals, No. 71 (4), pp. 823-830, 2018.

[5] Dudzik, K., Influence of friction stir welding on hardness distribution in joints of AW-5083 alloy, Journal of KONES Powertrain and Transport, Vol. 23, No. 3, pp. 101-106, 2016.

[6] Dudzik, K., Charchalis, A., Influence of Friction Stir Welding on Hardness Distribution in Joints of AlZn5Mg1 Alloy, Solid State Phenomena, Mechatronic Systems and Materials V, pp. 430-435, Trans Tech Publications, Switzerland 2013.

[7] Dudzik, K., Charchalis, A., Mechanical properties of 5083, 5059 and 7020 aluminium alloys and their joints welded by FSW, Journal of KONES Powertrain and Transport, Vol. 20, No. 2, pp. 69-73, 2013.

[8] Dudzik, K., Czechowski, M., Analysis of possible shipbuilding application of Friction Stir Welding (FSW) method to joining elements made of AlZn5Mg1 alloy, Polish Maritime Research, No. 4, pp. 37-40, 2009.

[9] Guo, N., Fu, Y., Wang, Y., Meng, Q., Zhu, Y., Microstructure and mechanical properties in friction stir welded 5 A06 aluminum alloy thick plate, Materials and Design, No. 113, pp. 273-283, 2017.

[10] Heidarzadeh, A., Saeid, T., Correlation between process parameters, grain size and hardness of friction-stir-welded Cu-Zn alloys, Rare Metals, No. 37(5), pp. 388-398, 2018.

[11] Hirata, T., Oguri, T., Hagino, H., Tsutomu, T. T., Chung, S. W., Takigawa, Y., Kenji, H. K., Influence of friction stir welding parameters on grain size and formability in 5083 aluminum alloy, Materials Science and Engineering, A 456, 2007.

[12] Lahti, K., FSW-possibilities in shipbuilding, Svetsaren, Vol. 58, No. 1, pp. 6-8, 2003.

[13] Patterson, E. E., Hovanski, Y., Field, D. P., Microstructural Characterization of Friction Stir Welded Aluminum-Steel Joints, Metallurgical and Materials Transactions A, Vol. 47A, pp. 2815-2829, June 2016.

[14] Yazdipour, A., Heidarzadeh, A., Dissimilar butt friction stir welding of Al 5083-H321 and $316 \mathrm{~L}$ stainless steel alloys, The International Journal of Advanced Manufacturing Technology, Vol. 87, pp. 3105-3112, 2016.

Manuscript received 01 August 2019; approved for printing 09 December 2019 